\title{
Oleanolic acid potentiates the antitumor activity of 5-fluorouracil in pancreatic cancer cells
}

\author{
JIANTENG WEI ${ }^{1,3}$, HAIZHOU LIU ${ }^{1}$, MING LIU $^{1}$, NING WU ${ }^{1}$, JIN ZHAO $^{1,3}$, \\ LIN XIAO $^{1,3}$, LIJUN HAN ${ }^{1}$, EDWARD CHU ${ }^{4}$ and XIUKUN LIN ${ }^{1,2}$ \\ ${ }^{1}$ Institute of Oceanology, Chinese Academy of Sciences, Qingdao 266071; ${ }^{2}$ Department of Pharmacology, \\ Capital Medical University, Beijing $100069 ;{ }^{3}$ Graduate University, Chinese Academy of Sciences, \\ Beijing 100049, P.R. China; ${ }^{4}$ University of Pittsburgh Cancer Institute, Pittsburgh, PA 15232, USA
}

Received March 30, 2012; Accepted April 26, 2012

DOI: 10.3892/or.2012.1921

\begin{abstract}
The antitumor activity of oleanolic (OA) has attracted attention due to its marked antitumor effects and pharmacological safety. In the present study, the effects of the combination of OA and 5-fluorouracil (5-FU) on Panc-28 human pancreatic cells were studied. The results showed that combined use of $\mathrm{OA}$ and 5-FU synergistically potentiated cell death effects on Panc-28 cells, and the pro-apoptotic effects were also increased. Further study revealed that the combined treatment could enhance mitochondrial depolarization, lysosomal membrane permeabilization (LMP) and leakage of cathepin D, while the release of cytochrome $\mathrm{C}$ did not display significant changes. The expression of apoptosis related proteins was also affected in cells treated with the combination of OA and 5-FU, including activation of caspases-3 and the expression of Bcl-2/Bax, survivin and $\mathrm{NF}-\kappa \mathrm{B}$. Our results provide evidence that combination of $\mathrm{OA}$ and 5-FU may serve as a novel strategy for the treatment of pancreatic cancer.
\end{abstract}

\section{Introduction}

Pancreatic cancer is the fourth leading cause of cancer death in the United States, with an estimated 43,140 new cases and 36,800 deaths in 2010 (1). Patients diagnosed with pancreatic cancer typically have a poor prognosis due to lack of early diagnostic symptoms and effective treatments $(2,3)$. Therefore, efforts to treat pancreatic cancer have been directed towards developing alternative modalities of therapy.

5-fluorouracil (5-FU), as a chemotherapy agent, is widely used for the treatment of solid tumors such as pancreatic cancer. It can also induce apoptosis in some sensitive cancer cell lines by blocking the activity of thymidylate synthase (4). However,

Correspondence to: Dr Xiukun Lin, Institute of Oceanology, Chinese Academy of Sciences, 7 Nanhai Rd, Qingdao 266071, P.R. China E-mail: linxiukun@yahoo.com

Key words: apoptosis, oleanolic acid, 5-fluorouracil, pancreatic cancer cells, synergism
5-FU presents the disappointing chemotherapeutic effectiveness due to side effects and multiple drug resistance $(5,6)$. Attempts to solve these problems have taken various approaches, including the combined use of cancer drugs. It is recently shown that combined treatment with various anticancer drugs increases the efficiency and reduces the cytotoxicity of some cancer drugs (7-12).

Natural products have been a successful source of therapeutic agents and drug leads. Oleanolic acid (OA) belongs to the group of pentacyclic triterpenes, which is widely distributed in fruits and some medicinal herbs (13). It has been reported that OA has antioxidant (14), antiinflammatory (15), antidiabetic (16), antimutagenicity (17) and antitumor (18) properties. Recently, the antitumor activity of OA has attracted more attention due to its marked antitumor effects and pharmacological safety. Our recent study reveals that $\mathrm{OA}$ induces cell death significantly via ROS-mediated mitochondrial pathway in human Panc-28 cells (19). However, the combined effects of OA and 5-FU in inhibiting cancer cell proliferation and inducing apoptosis have not been investigated.

In the present study, the effects of OA combined with 5-FU on cellular proliferation and apoptosis in human pancreatic cancer Panc-28 cells were studied and the underlined mechanism is also presented.

\section{Materials and methods}

Materials. Antibodies against caspase-3,-9, Bcl-2, Bax, survivin, cytochrome C, cathepsin D, p53 and NF- $\kappa \mathrm{B}$ were purchased from Santa Cruz Biotechnology, Inc. Anti-mouse or anti-rabbit antibodies were purchased from Beijing Solarbio Science \& Technology Co., Ltd.

Cell line and cell culture. Panc-28, a human pancreatic cancer cell line, was cultured in DMEM/F12 supplemented with $10 \%$ FBS plus antibiotics of penicillin and streptomycin (Sigma) at $37^{\circ} \mathrm{C}$ in $5 \% \mathrm{CO}_{2}$ in air. Cells were grown in 96-, 24- and 6-well plates.

Oleanolic acid and 5-fluorouracil treatment. OA (Sigma) and 5-FU (Sigma) were dissolved in dimethylsulfoxide (DMSO). Cells were pretreated with OA for $12 \mathrm{~h}$. Then, the supernatant 
fluid containing OA was removed and the fresh medium containing 5-FU was added, and were incubated at $37^{\circ} \mathrm{C}$ for another $24 \mathrm{~h}$ and harvested for the following examinations.

MTT assay. Inhibition of cell proliferation by OA was measured by MTT assay (20). Briefly, cells were grown in a 96-well plate $\left(5 \times 10^{3} / 200 \mu \mathrm{l} / \mathrm{well}\right)$ overnight, and were treated with OA $(20$, 30 and $40 \mu \mathrm{g} / \mathrm{ml}$ ) for $12 \mathrm{~h}$, and then the supernatant fluid was removed. The fresh medium with 5-FU $(10 \mu \mathrm{g} / \mathrm{ml})$ was added. After incubation for another $24 \mathrm{~h}, 40 \mu \mathrm{l}$ of MTT solution ( $5 \mathrm{mg} /$ $\mathrm{ml}$ ) was added to each well. After incubation for additional $4 \mathrm{~h}$, the formazan precipitate was dissolved in $150 \mu 1 \mathrm{DMSO}$, and then the absorbance at $490 \mathrm{~nm}$ was measured using ELx808 ${ }^{\mathrm{TM}}$ Absorbance Microplate Reader (BioTek, USA). The nature of the interactions between studied drugs was estimated by using published methods $(21,22)$, based on the principles described by Chou and Talalay $(23,24)$. Briefly, the expected value of combination effect between treatment with $\mathrm{OA}$ and treatment with 5-FU is calculated by the following formula: [(observed treatment with OA value)/(control value)] x [(observed treatment with 5-FU value)/(control value)] $\mathrm{x}$ (control value), and the coefficient of drug interaction (CDI) is calculated as (observed value)/ (expected value). CDI of $<1$ indicates a synergistic effect and $\mathrm{CDI}$ of $>1$ indicates a less than additive or an antagonistic effect.

Flow cytometry analysis. Flow cytometry analysis was performed as described by Luo et al (25). Briefly, apoptosis was assessed by the binding of annexin V-FITC to phosphotidylserine, which was externalized to the outer leaflet of the plasma membrane. Cells treated with OA $(30 \mu \mathrm{g} / \mathrm{ml})$ and $5-\mathrm{FU}(10 \mu \mathrm{g} / \mathrm{ml})$ were resuspended in the binding buffer (Nanjing KeyGen Biotech Co., Ltd., China) and reacted with $5 \mu \mathrm{l}$ of annexin V-FITC reagent and $5 \mu \mathrm{l}$ of PI for $30 \mathrm{~min}$ at room temperature in the dark. Stained cells were analyzed by flow cytometry.

DNA fragmentation analysis. DNA fragmentation was analyzed by agarose gel electrophoresis (26). Cells untreated or treated with 5-FU, OA or their combination were collected by centrifugation and washed with PBS. Total DNA was purified with a universal genomic DNA extraction kit (Takara Biotechnology Co., Ltd, China) according to the manufacturer's instructions. The DNA was resolved in $2 \%$ agarose gel and visualized by ultraviolet illumination (the Bio-Rad Chemi Doc XRS imaging system, USA) after staining with ethidium bromide.

Measurement of mitochondrial membrane potential (MMP). The uptake of the cationic fluorescent dye rhodamine 123 was used for the estimation of mitochondrial membrane potential (27). Cells untreated or treated with reagents as described above were harvested and washed twice with PBS. The cell pellets were then resuspended in $2 \mathrm{ml}$ fresh medium containing rhodamine $123(2.0 \mu \mathrm{M})$ and incubated at $37^{\circ} \mathrm{C}$ for 10 min with gentle shaking. Cells were collected by centrifugation and washed twice with PBS, then analyzed by fluorescence microscopy and fluorescence spectrophotometer (excitation $507 \mathrm{~nm}$, emission $529 \mathrm{~nm})$.

Measurement of lysosomal membrane permeabilization (LMP). LMP was measured by the lysosomotropic base and metachromatic fluorochrome acridine orange as described previously
(28). Briefly, cells untreated or treated with reagents as described above were stained with acridine orange $(0.005 \mu \mathrm{g} / \mathrm{ml}$, Sigma) for $6 \mathrm{~min}$ at $37^{\circ} \mathrm{C}$ without $\mathrm{CO}_{2}$. Immediately after staining, cells were analyzed by fluorescence microscopy.

Western blot analysis. Western blot analysis was performed as previously described (29) to determine the effect of OA and 5-FU on anti-/pro-apoptotic proteins, cells untreated or treated with OA, 5-FU or their combination were harvested by centrifugation at $3000 \mathrm{~g}$ for $10 \mathrm{~min}$, washed twice with ice-cold PBS, and lysed with RIPA buffer containing fresh protease inhibitor mixture $(50 \mu \mathrm{g} / \mathrm{ml}$ aprotinin, $0.5 \mathrm{mM}$ phenylmethanesulfonyl fluoride (PMSF), $1 \mathrm{mM}$ sodium orthovanadate, $10 \mathrm{mM}$ sodium fluoride and $10 \mathrm{mM} \beta$-glycerolphosphate). Proteins were quantified using the BCA protein assay (Biocolor BioScience \& Technology, China). Protein samples were resolved on 10-15\% SDS-polyacrylamide gels transferred to nitrocellulose membranes and probed with protein specific antibodies followed by treatment with HRP-conjugated secondary antibody. The relative quantity of protein were analyzed by Gel-Pro Analyzer software.

Statistical analysis. All of the experiments were performed at least three independent experiments, and the data are presented as the mean $\pm \mathrm{SD}$. The statistical significance of the mean difference between the control and treated groups was determined by a paired $t$-test. $\mathrm{P}<0.05$ was considered statistically significant.

\section{Results}

OA potentiates the 5-FU effect on proliferation inhibition in Panc-28 cells. In order to determine the effect of OA and 5-FU on Panc-28 cells, the respective cell viability of OA and 5-FU were measured by MTT assay. As shown in Fig. 1A, the proliferation was decreased to 98,95 and $64 \%$ in Panc-28 cells treated with 20,30 and $40 \mu \mathrm{g} / \mathrm{ml} \mathrm{OA}$, respectively, while the viability of Panc-28 cells treated with $10 \mu \mathrm{g} / \mathrm{ml} 5$-FU was $\sim 84 \%$. However, in the present of OA $(20,30$ and $40 \mu \mathrm{g} / \mathrm{ml})$, the cell viability was decreased to 57,41 , and $15 \%$, respectively. The CDIs were 0.69 , 0.58 and 0.37 respectively (Fig. 1B). This result indicates that the combined treatment increases the inhibition effect on Panc-28 cells, and OA synergistically potentiates the effect of 5-FU on the growth inhibition of human pancreatic Panc-28 cells.

Combined treatment with $O A$ and 5-FU potentiates apoptosis induction in Panc-28 cells. As have been confirmed earlier, OA or 5-FU induced cell death in apoptotic pathway $(19,30,31)$. We next determine if the combination of the two compounds increases the apoptotic effect. As shown in Fig. 2, the average percentage of apoptotic cells increased significantly when treating the cells with either $\mathrm{OA}$ or 5-FU; the apoptotic rate was 4.78 and $7.14 \%$ in cells treated with $\mathrm{OA}(30 \mu \mathrm{g} / \mathrm{ml})$ or 5 -FU $(10 \mu \mathrm{g} / \mathrm{ml})$ respectively. However, combinations of the two reagents produced significant increase in apoptotic cells; the apoptotic rate induced by combination treatment increased to $35.33 \%$ (Fig. 2A and B). In addition, fragments of degraded DNA were visible in Panc-28 cells after treatment with the combination of OA (30 $\mu \mathrm{g} / \mathrm{ml})$ and $5-\mathrm{FU}(10 \mu \mathrm{g} / \mathrm{ml})$, while OA or 5-FU alone did not induce DNA fragmentation (Fig. 2C). The result reveals that the combined treatment with 


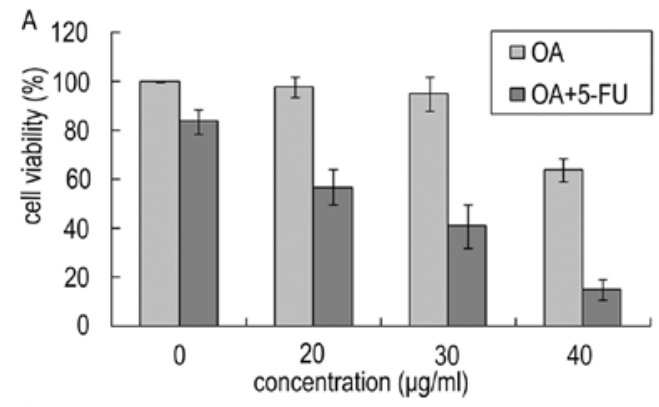

B

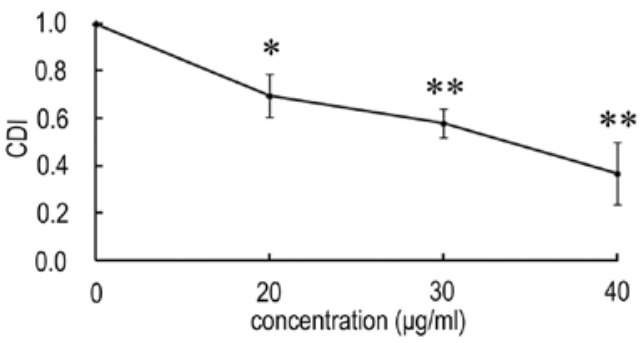

Figure 1. Inhibition of cell proliferation by the combination of OA and 5-FU in Panc- 28 cells. (A) The cell viability of cells treated with OA and 5-FU. (B) The coefficient of drug interaction (CDI) of treatment with OA and 5-FU. Cell viability and CDI were measured as described in Materials and methods. Data are presented as mean $\pm \mathrm{SD}$. Cell viability was obtained in three independent experiments. ${ }^{*} \mathrm{P}<0.05$ vs control; ${ }^{* *} \mathrm{P}<0.01$ vs control.

OA and 5-FU could enhance cell death via apoptotic pathway in Panc-28 cells.

Effect of combined treatment with OA and 5-FU on MMP in Panc-28 cells. To determine the underlining mechanism of apoptosis induced by the combination of OA and 5-FU, we measured the MMP change and the level of the cytochrome $\mathrm{C}$ in cytosol. As shown in Fig. 3A and B, treatment of the cells with OA at $30 \mu \mathrm{g} / \mathrm{ml}$ or $5-\mathrm{FU}$ at $10 \mu \mathrm{g} / \mathrm{ml}$ did not affect the fluorescence intensity significantly, and the fluorescence intensity of the cells treated with the combination of OA and 5-FU resulted in slight decrease of the fluorescence intensity as determined by fluorescence microscopy (Fig. 3A) and fluorescence spectrophotometer (Fig. 3B). We then checked the expression of cytochrome $\mathrm{C}$ and the results showed that the release of cytochrome $\mathrm{C}$ from mitochondria to cytosol was not changed in Panc-28 cells either treated with OA, 5-FU or treated with the combination of OA and 5-FU (Fig. $3 \mathrm{C})$. The results suggested that the enhancement of apoptosis induced by the combination of OA and 5-FU might not be mediated by the mitochondrial pathway.

Effect of combined treatment with OA and 5-FU on lysosomal membrane permeabilization (LMP) in Panc-28 cells. To determine if LMP is affected by the combination of OA and 5-FU, we analyzed the alterations in Panc-28 cells using acridine orange staining. The results showed that the fluorescence intensity of the cells treated with OA or 5-FU alone did not have a significant change, while the cells treated with the combination of OA and 5-FU displayed less intense red fluorescence and more intense green fluorescence (Fig. 4A). We next detected the level of cathepin D in Panc-28 cells, and the result showed that the level of cathepsin D in cytosol was elevated significantly in cells treated with the combination of OA and 5-FU compared to OA or 5-FU alone (Fig. 4B). The results indicated that the combined use of OA and 5-FU could enhance the LMP following the increase of cathepin D leakage and that LMP pathway may play an important role in the apoptosis induced by the combination of OA and 5-FU.
A

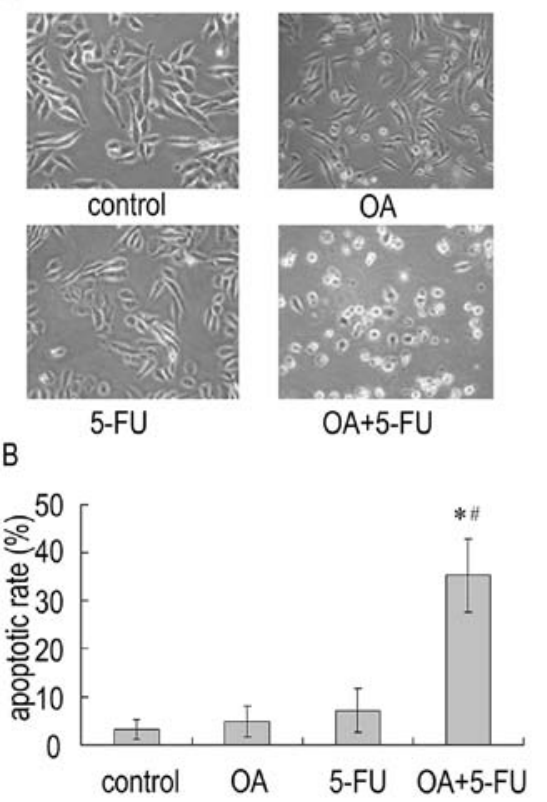

C

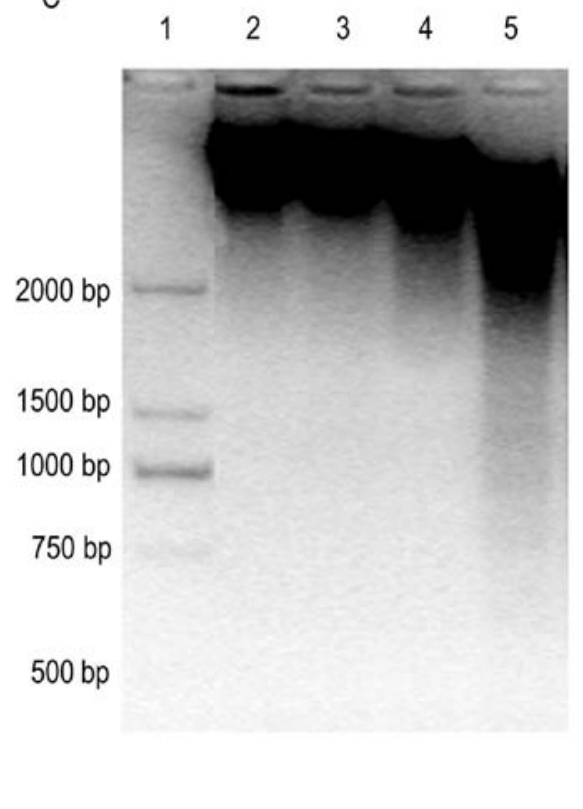

Figure 2. Apoptosis induced by the combination of OA and 5-FU in Panc-28 cells. Panc-28 cells were treated with OA ( $30 \mu \mathrm{g} / \mathrm{ml})$ for $12 \mathrm{~h}$ and then treated with 5-FU $(10 \mu \mathrm{g} / \mathrm{ml})$ for $24 \mathrm{~h}$. (A) Micrographs of Panc-28 cells treated with OA, 5-FU and the combination. (B) Flow cytometric analysis of apoptosis induced by OA, 5-FU and the combination in Panc-28 cells. (C) Electrophoresis results of DNA extract of Panc-28 cells in untreated (lane 2) and treated with OA (lane 3), 5-FU (lane 4) and the combination (lane 5). Data were obtained in three independent experiments and the representative results are shown. $\mathrm{P}<0.01 \mathrm{vs}$ control; ${ }^{*} \mathrm{P}<0.01 \mathrm{vs}$ cells treated with OA or 5-FU alone. 
A

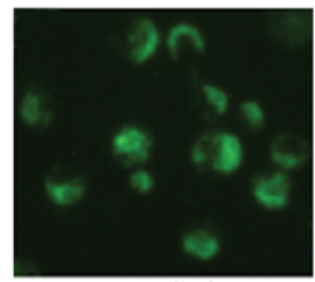

control

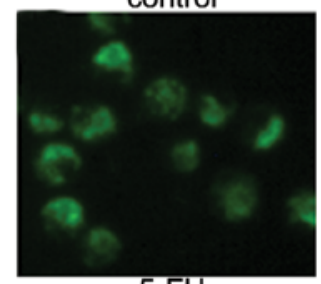

5-FU

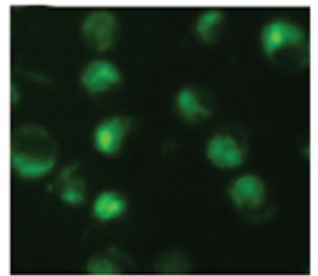

$\mathrm{OA}$

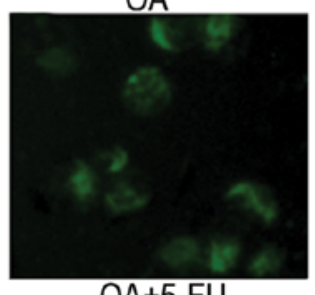

$\mathrm{OA}+5-\mathrm{FU}$
B

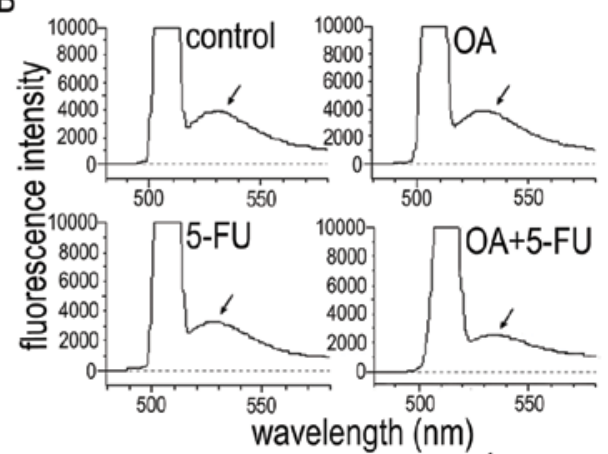

C

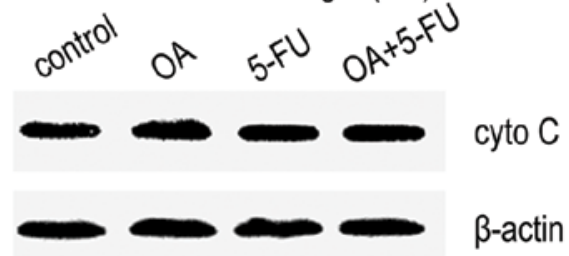

Figure 3. Mitochondrial membrane potential (MMP) and cytochrome C level in Panc-28 cells treated with the combination of OA and 5-FU. Panc-28 cells were untreated or treated with $\mathrm{OA}(30 \mu \mathrm{g} / \mathrm{ml}), 5-\mathrm{FU}(10 \mu \mathrm{g} / \mathrm{ml})$ and the combination. Cells were stained with mitochondrial dye rhodamine $123(2.0 \mu \mathrm{M})$ for $10 \mathrm{~min}$ at $37^{\circ} \mathrm{C}$ and washed with PBS. (A) The alteration of mitochondrial membrane potential (MMP) in Panc-28 cells treated with the combination of OA and 5-FU as observed under a fluorescence microscope. (B) The alteration of MMP in Panc-28 cells treated with the combination of OA and 5-FU as detected by fluorescence spectrophotometer. Arrow, the intensity of green fluorescence (excitation $507 \mathrm{~nm}$, emission $529 \mathrm{~nm}$ ). (C) The results of western blot analysis of cytochrome C expression. Data were obtained in three independent experiments and the representative results are shown.

A

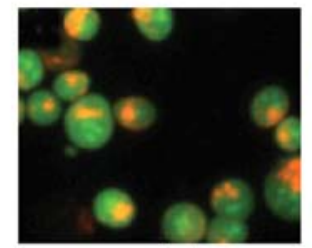

control

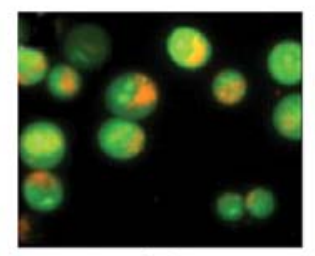

$\mathrm{OA}$

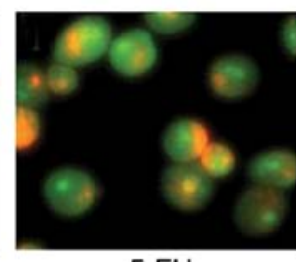

5-FU

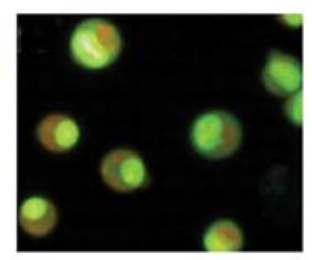

$\mathrm{OA}+5-\mathrm{FU}$

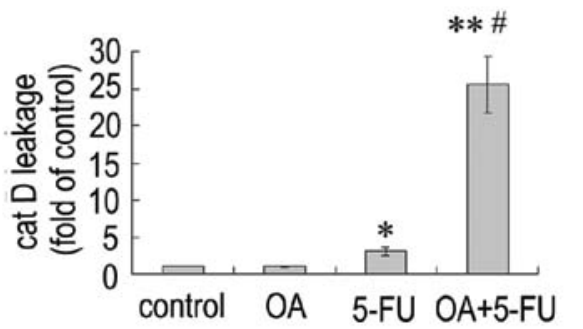

control $\mathrm{OA} \quad 5-\mathrm{FU} \mathrm{OA}+5-\mathrm{FU}$
B

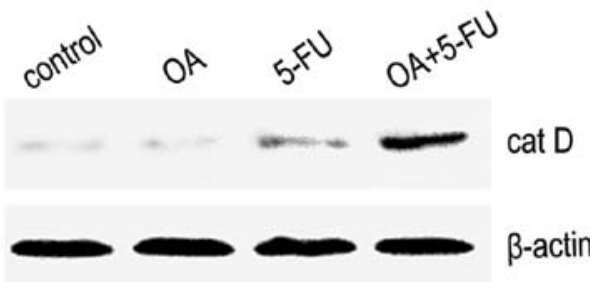

Figure 4. Lysosomal membrane permeabilization (LMP) and cathepin D leakage induced by the combination of OA and 5-FU in Panc-28 cell. Panc-28 cells were untreated or treated with $\mathrm{OA}(30 \mu \mathrm{g} / \mathrm{ml}), 5-\mathrm{FU}(10 \mu \mathrm{g} / \mathrm{ml})$ and the combination. Cells were stained with lysosomal dye acridine orange $(0.005 \mu \mathrm{g} / \mathrm{ml})$ for $6 \mathrm{~min}$ at $37^{\circ} \mathrm{C}$ without $\mathrm{CO}_{2}$. (A) The alteration of LMP in Panc-28 cells treated with the combination of OA and 5-FU as observed under a fluorescence microscope. (B) The results of western blot analysis of cathepin D expression. Data were obtained in three independent experiments and representative results are shown. ${ }^{*} \mathrm{P}<0.05$ vs control; ${ }^{* *} \mathrm{P}<0.01$ vs control; ${ }^{*} \mathrm{P}<0.01$ vs cells treated with $\mathrm{OA}$ or 5 -FU alone.

Combined treatment with $O A$ and 5-FU affects the activation of caspases in Panc-28 cells. Since caspases are the important mediators of apoptosis, we next checked the expression of caspases. As shown in Fig. 5, treatment the cells with the combination of OA and 5-FU resulted in a significant increase in caspase-3 activity compared to that treated with OA or 5-FU alone, while the activity of caspase-9 did not have a significant change (Fig. 5). The results further confirmed that the enhancement of apoptosis induced by the combination of OA and 5-FU was not dependent on the caspase- 9 mediated mitochondrial pathway.
Combined treatment with $O A$ and 5-FU affects the expression of apoptosis-related proteins in Panc-28 cells. The expression of Bax, and Bcl-2 was determined by western blot analysis. As shown in Fig. 6, the expression of Bax was increased, while the expression of $\mathrm{Bcl}-2$ was decreased significantly in cells treated by the combination of OA and 5-FU compared to that treated with OA or 5-FU alone (Fig. 6). Additionally, the combined treatment with OA and 5-FU inhibited the level of survivin in cytosol significantly (Fig. 6). Thus, the data confirmed that combination of OA and 5-FU could regulate the level of some apoptosis-related proteins. 


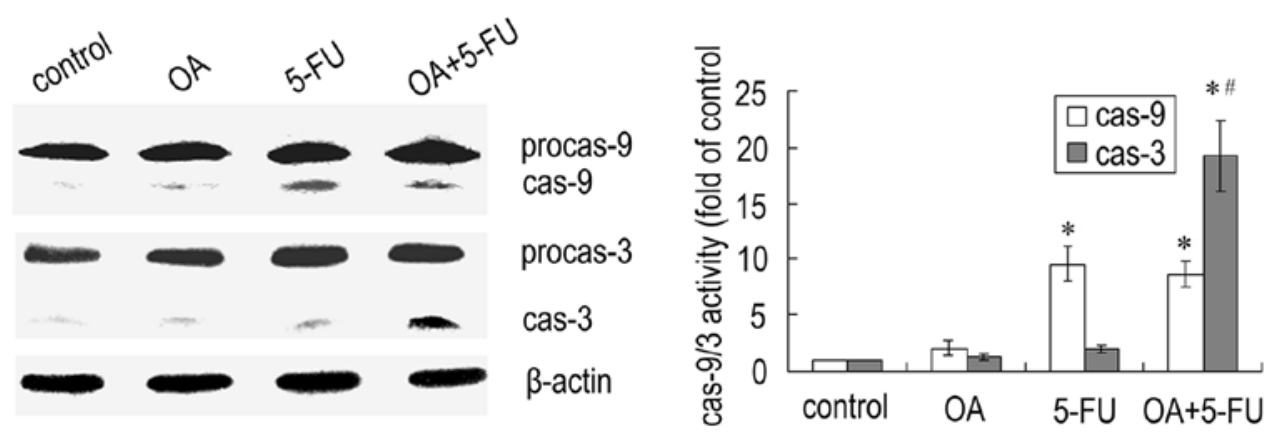

Figure 5. The activation of caspase-9/-3 by the combination of OA and 5-FU in Panc-28 cells. Panc-28 cells were treated with OA and 5-FU and then collected, washed and lysed with RIPA. The lysate was analyzed by western blot analysis as described in Materials and methods. Data were obtained in three independent experiments and representative results are shown. ${ }^{*} \mathrm{P}<0.05$ vs control; ${ }^{*} \mathrm{P}<0.05$ vs cells treated with OA or 5 -FU.

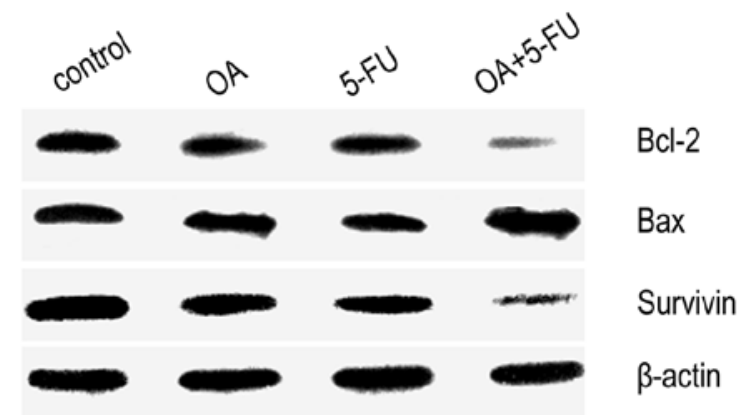

Figure 6. The alternation of apoptosis related proteins induced by the combination of OA and 5-FU in Panc-28 cells. Panc-28 cells were treated with OA and 5-FU and then collected, washed and lysed with RIPA. The lysate was analyzed by western blot analysis as described in Materials and methods. Data were obtained in three independent experiments and representative results are shown.

The expression of $\mathrm{p} 53$ and NF-kB was also determined by western blot analysis. Treatment of human pancreatic Panc-28 cells with OA alone did not affect the p53 expression (Fig. 7) and the p53 expression was increased in cells treated with 5-FU either in the presence or absence of OA (Fig. 7), suggesting that OA did not affect 5-FU induced p53 expression. However, in the presence of OA, the expression of NF- $\mathrm{KB}$ induced by $5-\mathrm{FU}$ was significantly increased (Fig. 7). These results suggest that NF- $\mathrm{KB}$ plays an important role in the apoptosis induced by the combination of OA and 5-FU in Panc-28 cells.

\section{Discussion}

In our previous study we confirmed that OA could induce pancreatic cancer cell apoptosis via ROS-mediated mitochondrial pathway and lysosomal pathway (19). In this study, we provide evidence that $\mathrm{OA}$ enhanced the inhibition of proliferation and increased apoptosis induced by 5-FU in Panc- 28 cells, and the CDI was associated with the concentration of OA. Therefore, the combination of OA and 5-FU should be considered as a potential regimen for the treatment of pancreatic cancer.

It is well documented that 5-FU could inhibit DNA proliferation in cancer cells by inhibiting the activity of thymidylate synthase, leading to apoptosis (32). OA induced cancer cell apoptosis via the mitochondria pathway following mitochondrial membrane potential loss and cytochrome $C$ release $(33,34)$. In our previous study we confirmed that OA could induce pancreatic cancer cells apoptosis via the ROS-mediated mitochondrial and lysosomal pathways (19). The present data showed that LMP and leakage of cathepsin D into cytosol was elevated in pancreatic cancer cells treated with the combination of OA and 5-FU. LMP caused lysosome damage and leakage of lysosomal constituents such as cathepsins. The leakage of cathepsin D could be sufficient to trigger apoptosis, since this enzyme can directly activate procaspase-3 (35). Cathepsin D could also cleave Bid following

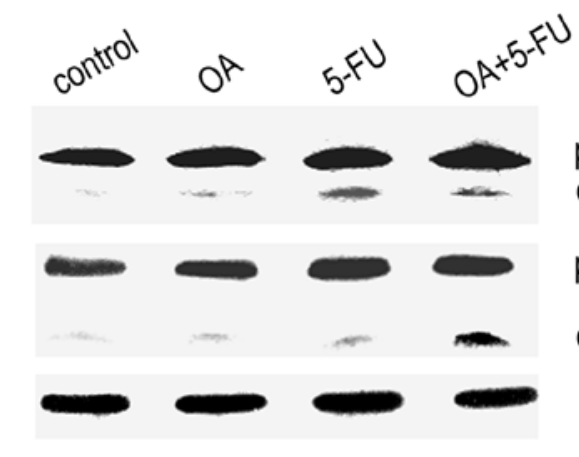

$\begin{array}{ll} & \\ \text { procas-9 } & \\ \text { cas-9 } & \\ \text { procas-3 } & \\ \text { cas-3 } & \\ \beta \text {-actin } & \end{array}$

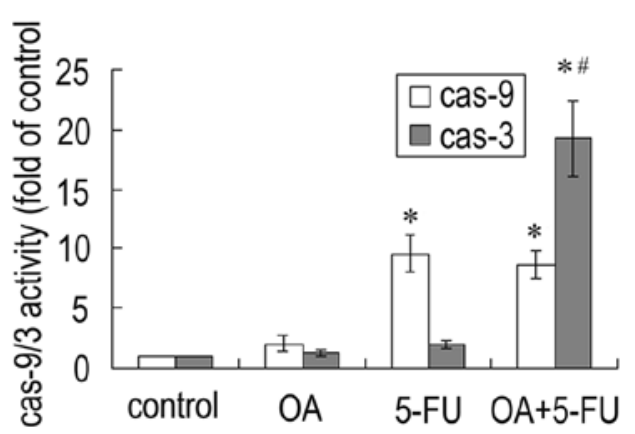

Figure 7. The expression of 533 and NF-kB induced by the combination of OA and 5-FU in Panc-28 cells. Panc-28 cells were treated with OA and 5-FU and then collected, washed and lysed with RIPA. The lysate was analyzed by western blot analysis as described in Materials and methods. Data were obtained in three independent experiments and representative results are shown. ${ }^{*} \mathrm{P}<0.05$ vs control; ${ }^{*} \mathrm{P}<0.05$ vs cells treated with OA or 5-FU alone. 
the start-up of mitochondrial pathway (36). However, our study revealed that mitochondrial pathway was not involved in the combination of OA and 5-FU induced cell apoptosis, since cytochrome $\mathrm{C}$ was not released and the activation of caspase- 9 was not enhanced in the cells treated with the combination regimen. Therefore, the lysosomal induced pathway may play a key role in the apoptotic pathway. As have been reported previously, some anticancer agents induce cell death via lysosomal apoptotic pathway (37); anthrax lethal toxin induces lysosomal membrane permeabilization and cathepsin release in RAW 264.7 cells (28).

$\mathrm{NF}-\kappa \mathrm{B}$, as a nuclear transcription factor, plays vital roles in immunity, inflammation, oxidative stress, cell proliferation and apoptosis (38). In this study, the results showed that treatment of the pancreatic cells with the combination of OA and 5-FU results in a significant increase of $\mathrm{NF}-\kappa \mathrm{B}$ expression, suggesting that $\mathrm{NF}-\kappa \mathrm{B}$ mediated cell apoptosis plays a key role in the biological process induced by the combination of OA and 5-FU in Panc-28 cells. It is well documented that activation of $\mathrm{NF}-\kappa \mathrm{B}$ can affect the pro-apoptotic targets including the death receptors Fas (CD95), TRAIL receptors DR4, DR5 and DR6, the deathinducing ligands FasL, TNF $\alpha$ and TRAIL, tumor suppressor p53 and the Bcl-2 family member Bax and the proapoptotic alternatively spliced form of Bcl-xL, Bcl-xS (39). In this study, the expression of Bax increased and the Bcl-2 expression was decreased, when cells were treated with the combination of $\mathrm{OA}$ and 5-FU. It is conceivable that the increased expression of caspase-3 induced by the treatment of combination of OA and 5-FU may be related with death receptor apoptotic pathway. Additionally, NF- $\kappa \mathrm{B}$ can also enhance cell death via upregulation of the tumor suppressor CYLD, leading to disassembly of the IKK complex (39). Further study is in progress in our laboratory to address the more complicated mechanisms.

In conclusion, the present study provides solid evidence that the combination of OA and 5-FU was able to increase the growth inhibition of Panc-28 cells and the induction of apoptosis via lysosomal-mediated leakage of cathepsin D. Some apoptotic proteins such as caspase- $3, \mathrm{NF}-\kappa \mathrm{B}$, and $\mathrm{Bcl}-2$ play important roles in the apoptotic pathway induced by the combination regimen. In vivo studies using xenograft tumor mice are needed to reveal whether the combination treatment would enhance the growth inhibition of pancreatic tumors.

\section{Acknowledgements}

This study was supported by the State Innovative Drugs Development Program of China (2009ZX09103-661 and 2009ZX09102).

\section{References}

1. Jemal A, Siegel R, Xu J and Ward E: Cancer statistics. CA Cancer J Clin 60: 277-300, 2010.

2. Chua YJ and Zalcberg JR: Pancreatic cancer-is the wall crumbling? Ann Oncol 119: 1224-1230, 2008.

3. Pierantoni C, Pagliacci A, Scartozzi M, Berardi R, Bianconi M and Cascinu S: Pancreatic cancer: progress in cancer therapy. Crit Rev Oncol Hematol 67: 27-38, 2008.

4. Hwang PM, Bunz F, Yu J, Rago C, et al: Ferredoxin reductase affects p53-dependent, 5-fluorouracil-induced apoptosis in colorectal cancer cells. Nat Med 7: 1111-1117, 2001.

5. Malet-Martino M and Martino R: Clinical studies of three oral prodrugs of 5-fluorouracil (Capecitabine, UFT, S-1): a review. Oncologist 7: 288-323, 2002.
6. Li D, Xie K, Wolff R and Abbruzzese JL: Pancreatic cancer. Lancet 363: 1049-1057, 2004

7. Borja-Cacho D, Yokoyama Y, Chugh RK, et al: TRAIL and triptolide: an effective combination that induces apoptosis in pancreatic cancer cells. J Gastrointest Surg 14: 252-260, 2010.

8. Dizaji MZ, Malehmir M, Ghavamzadeh A, Alimoghaddam K and Ghaffari SH: Synergistic effects of arsenic trioxide and silibinin on apoptosis and invasion in human glioblastoma U87MG cell line. Neurochem Res 37: 370-380, 2012.

9. Menéndez JA, Barbacid MM, Montero S, et al: Effects of gammalinolenic acid and oleic acid on paclitaxel cytotoxicity in human breast cancer cells. Eur J Cancer 37: 402-413, 2001.

10. Nakagawa T, Shimizu M, Shirakami Y, et al: Synergistic effects of acyclic retinoid and gemcitabine on growth inhibition in pancreatic cancer cells. Cancer Lett 273: 250-256, 2009.

11. Yagil H, Yotsumoto F, Sonoda1 K, Kuroki M, Mekada E and Miyamoto S: Synergistic anti-tumor effect of paclitaxel with CRM197, an inhibitor of HB-EGF, in ovarian cancer. Int J Cancer 124: 1429-1439, 2009.

12. Sei S, Mussio JK, Yang Q, et al: Synergistic antitumor activity of oncolytic reovirus and chemotherapeutic agents in non-small cell lung cancer cells. Mol Cancer doi:10.1186/1476-4598-8-47, 2009.

13. Liu J: Oleanolic acid and ursolic acid: research perspectives. J Ethnopharmacol 100: 92-94, 2005.

14. Wang X, Ye X, Liu R, et al: Antioxidant activities of oleanolic acid in vitro: possible role of Nrf2 and MAP kinases. Chem Biol Interact 184: 328-337, 2010.

15. Rubén M, Juliana CT, Marita, Mercedes A, Valentina RG and María LN: Beneficial actions of oleanolic acid in an experimental model of multiple sclerosis: a potential therapeutic role. Biochem Pharmacol 79: 198-208, 2010.

16. Teodoro T, Zhang L, Alexander T, Yue J, Vranic M and Volchuk A: Oleanolic acid enhances insulin secretion in pancreatic $\beta$-cells. FEBS Lett 582: 1375-1380, 2008

17. Resende FA, Barcala CA, Faria MC, Kato FH, Cunha WR and Tavares DC: Antimutagenicity of ursolic acid and oleanolic acid against doxorubicin-induced clastogenesis in Balb/c mice. Life Sci 79: 1268-1273, 2006.

18. Liu J: Pharmacology of oleanolic acid and ursolic acid. J Ethnopharmacol 49: 57-68, 1995.

19. Wei J, Liu M, Liu H, et al: Oleanolic acid arrests cell cycle and induces apoptosis via ROS-mediated mitochondrial depolarization and lysosomal membrane permeabilization in human pancreatic cancer cells. J Appl Toxicol (In press).

20. Mosmann T: Rapid colorimetric assay for cellular growth and survival: Application to proliferation and cytotoxicity assays. J Immunol Methods 65: 55-63, 1983.

21. Mai Z, Blackburn GL and Zhou J: Soy phytochemicals synergistically enhance the preventive effect of tamoxifen on the growth of estrogen-dependent human breast carcinoma in mice. Carcinogenesis 28: 1217-1223, 2007.

22. Mao CY, Hua HJ, Chen P, Yu DC, Cao J and Teng LS: Combined use of chemotherapeutics and oncolytic adenovirus in treatment of AFP expressing hepatocellular carcinoma. Hepatobiliary Pancreat Dis Int 8: 282-287, 2009.

23. Chou TC and Talalay P: Analysis of combined drug effects: a new look at a very old problem. Trends Pharmacol Sci 4: 450-454, 1983.

24. Chou TC and Talalay P: Quantitative analysis of dose-effect relationships: the combined effects of multiple drugs or enzyme inhibitors. Adv Enzyme Regul 22: 27-55, 1984.

25. Luo M, Liu X, Zua Y, Fu Y, Zhang S, Yao L and Efferth T: Cajanol, a novel anticancer agent from Pigeonpea [Cajanus cajan (L.) Millsp.] roots, induces apoptosis in human breast cancer cells through a ROS-mediated mitochondrial pathway. Chem Biol Interact 188: 151-160, 2010.

26. Ning X, Zhao J, Zhang Y, Cao S, Liu M, Ling P and Lin X: A novel anti-tumor protein extracted from Meretrix meretrix Linnaeus induces cell death by increasing cell permeability and inhibiting tubulin polymerization. Int J Oncol 35: 805-812, 2009.

27. Cao J, Liu Y, Jia L, et al: Curcumin induces apoptosis through mitochondrial hyperpolarization and mtDNA damage in human hepatoma G2 cells. Free Radic Biol Med 43: 968-975, 2007.

28. Averette KM, Pratt MR, Yang Y, et al: Anthrax lethal toxin induced lysosomal membrane permeabilization and cytosolic cathepsin release is Nlrplb/Nalplb-dependent. PLoS One 4: e7913, 2009.

29. Zhang Y, Yang S, Liu M, et al: Interaction between thymidylate synthase and its cognate mRNA in zebrafish embryos. PLoS One 5: e10618, 2010. 
30. Tong D, Poot M,Hu D and Oda D: 5-fluorouracil-induced apoptosis in cultured oral cancer cells. Oral Oncol 36: 236-241, 2000.

31. Warr JR, Bamford A and Quinn DM: The preferential induction of apoptosis in multidrug-resistant KB cells by 5 -fluorouracil. Cancer Lett 175: 39-44, 2002.

32. Sugamura K, Makino M, Shirai H, Kimura O, Maeta M, Itoh $\mathrm{H}$ and Kaibara N: Enhanced induction of apoptosis of human gastric carcinoma cells after preoperative treatment with 5-fluorouracil Cancer 79: 12-17, 1997.

33. Feng L, Au-Yeung W, Xu YH, Wang SS, Zhu Q and Xiang P: Oleanolic acid from Prunella Vulgaris L. induces SPC-A-1 cell line apoptosis via regulation of $\mathrm{Bax}, \mathrm{Bad}$ and $\mathrm{Bcl}-2$ expression. Asian Pac J Cancer Prev 12: 403-408, 2011.

34. Shyu MH, Kao TC and Yen GC: Oleanolic acid and ursolic acid induce apoptosis in $\mathrm{HuH} 7$ human hepatocellular carcinoma cells through a mitochondrial-dependent pathway and downregulation of XIAP. J Agric Food Chem 58: 6110-6118, 2010.

35. Hishita T, Tada-Oikawa S, Tohyama K, et al: Caspase-3 activation by lysosomal enzymes in cytochrome c-independent apoptosis in myelodysplastic syndrome-derived cell line P39. Cancer Res 61 : 2878-2884, 2001.
36. Reiners JJ, Caruso JA, Mathieu P, Chelladurai B, Yin XM and Kessel D: Release of cytochrome $c$ and activation of pro-caspase- 9 following lysosomal photodamage involves Bid cleavage. Cell Death Differ 9: 934-944, 2002.

37. Servais H, van Der Smissen P, Thirion G, van der Essen G, van Bambeke F, Tulkens PM and Mingeot-Leclercq MP: Gentamicin-induced apoptosis in LLC-PK1 cells: involvement of lysosomes and mitochondria. Toxicol Appl Pharm 206: 321-333, 2005.

38. Bian X,McAllister-Lucas LM, Shao F, et al: NF-kappa B activation mediates doxorubicin-induced cell death in N-type neuroblastoma cells. J Biol Chem 276: 48921-48929, 2001.

39. Dutta J, Fan Y, Gupta N, Fan G and Gélinas C: Current insights into the regulation of programmed cell death by NF- $\mathrm{KB}$. Oncogene 25: 6800-6816, 2006. 